\title{
ESBOZOS DEL PROTOCOLO DIPLOMATICO Y SU DESARROLLO EN EL TIEMPO BAJO EL PRISMA DE LA COMUNICACIÓN
}

\author{
Mariana SUELDO ${ }^{1}$ \\ Beata GREBLIAUSKIENE ${ }^{2}$
}

\begin{abstract}
RESUMEN
El artículo presenta un análisis del protocolo diplomático bajo el prisma del proceso de comunicación. Se analiza el aspecto comunicativo del protocolo diplomático, considerado como herramienta o medio para garantizar una comunicación efectiva y libre de ambigüedades. Se tratan también las causas y circunstancias que han dado origen a las diferentes facetas características del protocolo diplomático a lo largo de su desarrollo histórico, así como los factores más determinantes o influyentes en algunas de estas etapas de su evolución. El protocolo diplomático como parte del proceso de comunicación es analizado bajo diferentes aspectos, tales como: los fines primarios y secundarios que persiguen las partes activas en el proceso de comunicación, las aptitudes comunicativas de estos sujetos, el constantemente creciente número de agentes que toman parte en estos procesos de comunicación (diplomática) y la intensidad o aumento de las ocasiones o eventos comunicativos de ésta índole debido a los avances tecnológicos y su innegable impacto en el desempeño de la tarea diplomática. El presente artículo hace también mención a la variabilidad de los fines que puede tener el protocolo diplomático, cubriendo un espectro que puede ir desde evitar las ambigüedades o malos entendidos, hasta el objetivo claro o velado de la mera persuasión. Finalmente, se presentan algunas consideraciones sobre el uso del lenguaje no verbal, propio del protocolo diplomático, aunque no necesariamente inherente al mismo. También se presenta una reseña de los abundantes rituales y ceremonias en boga en el Medioevo, como periodo significativamente representativo para la formación y posterior desarrollo del protocolo diplomático, y el paso de la prueba impuesta por la Revolución Francesa, para llegar al protocolo de nuestros días.

Palabras claves: protocolo diplomático, proceso de comunicación, desarrollo del protocolo diplomático, factores.
\end{abstract}

\footnotetext{
ABSTRACT

1 ISM Universidad de Ciencias Empresariales y Económicas (ISM University of Management and Economics) Profesora adjunta (Senior assistant professor) - Vilnius. Lituania.

C.E: mariana.sueldo@ism.lt

${ }^{2}$ Universidad de Vilnius, Facultad de Comunicación - Profesora Adjunta (Associate professor) Vilnius. Lituania.

C.E: beata.grebliauskiene@,kf.vu.lt
}

Fecha de recepción del artículo:Octubre 2010

Fecha de evaluación:Noviembre 2010 
This paper provides an analysis of diplomatic protocol and its development through the prism of communication. Protocol being understood as a means to ensure effective and clear communication, the circumstances and reason for the emergence of protocol are discussed with a further overview of the most influential factors within the process of diplomatic protocol development. Three main factors are here considered as the most significant, namely: the uncertainty involved in any communicational situation, the literacy level of individuals taking part in such situations, and the intentional changes brought into all areas of human performance, and within the process of diplomatic communication, the primary and secondary aims pursued by communication agents.

This article unveils these factors within the area of communication, focusing respectively on each of them, at the same drawing a chronological parallel that covers the most significant periods and hallmarks within the historical line of diplomatic protocol development. The avoidance of uncertainty, natural to any individual, is assisted by ritualized and rule-base interpersonal communication as a means to reduce such uncertainty. Then the considerable impact that an individual's self-expression abilities and comprehension skills can have on effective communication are discussed, from the early medieval times of nonverbal and symbolic communication, through late medieval European court mannerism to postrevolutionary and modern use of a more egalitarian communication style. Finally, the article provides some insight into the unquestionable impact that information and telecommunication technological advances have had on the intensification, speed, quality and purpose of modern diplomatic communication as well as on diplomatic protocol as its common code.

Key words: diplomatic protocol, communication process, development of diplomatic protocol, factors.

\section{RESUMÉ}

L'article présente une analyse du protocole diplomatique sous le rapport du processus de communication. Y est analysé l'aspect communicatif du protocole diplomatique, considéré comme outil ou moyen de garantir une communication efficace et libre de toute ambigüité.

Sont traités également les causes et les circonstances qui ont donné origine aux différentes facettes caractéristiques du protocole diplomatique tout au long de son déroulement historique, ainsi que les facteurs les plus déterminants ou influents dans certaines étapes de son évolution. Le protocole diplomatique comme partie du processus de communication est analysé sous les aspects suivants : les fins primaires et secondaires que poursuivent les parties actives dans le processus de communication, les aptitudes communicatives des sujets, le numéro continuellement croissant des agents qui prennent part dans ces processus de communication (diplomatie) et l'intensité ou croissance des occasions ou évènements communicatifs de cette nature due aux avancées techniques et son impact incomparable dans l'accomplissement de la tâche diplomatique. Le présent article fait également mention de la diversité des fins que peut avoir le protocole diplomatique, couvrant un spectre qui peut aller d'éviter les ambigüités ou les malentendus, à l'objectif clair ou voilé de la simple persuasion.

Finalement, sont présentés quelques considérations sur l'utilisation du langage non verbal, propre du protocole diplomatique, bien que non nécessairement inhérent à lui-même. Aussi est présenté un compte rendu des nombreux rituels et cérémonies en vogue au Moyen Âge, comme période significativement représentative pour la formation et le déroulement ultérieur du protocole diplomatique, et le passage de l'épreuve imposée par la Révolution Française, pour arriver au protocole de nos jours.

Mots clés : protocole diplomatique, processus de communication, développement du protocole diplomatique, facteurs.

\section{Introducción}

El protocolo diplomático moderno se caracteriza por su ceremonialidad y abundantes gestos de estudiada cortesía. No faltan hoy en día estudiosos del tema, ya sean teoréticos o pragmáticos, 
quienes sostienen que las formalidades de la etiqueta del mundo actual carecen de importancia o interés para el ciudadano ordinario. Más aún, muchos de los agentes que toman parte activa en asuntos internacionales, o bien no tienen los mínimos conocimientos sobre protocolo, o ni siquiera se percatan de la necesidad de aprender las sutilezas de este arte y hacen caso totalmente omiso de estas normas. Tal vez se puedan justificar esgrimiendo el argumento de su poder para dar curso a la historia mundial y de los buenos resultados que algunos han alcanzado aunque no se apliquen a las sutilezas de la diplomacia protocolar.

Dicha postura empezó a cobrar vuelo ya en el Modernismo Temprano, cuando los diplomáticos de entonces pensaban que las ceremonias eran innecesarias, que eran una mera formalidad vacía de contenido, una pérdida de valioso tempo. Asistirían obviamente a las recepciones y eventos que requerían su presencia, sí, dedicarían su tiempo a estas inocentes ocasiones de aplicar normas protocolares, pero no sin un dejo de criticismo a la futilidad de las mismas.

Los historiadores parecen tener una postura de doble entrada con respecto al protocolo diplomático. Algunos lo consideran un espectáculo y al referirse al mismo usan términos peyorativos, tales como "prácticas absurdas", "innecesarias susceptibilidades". Para otros, que escribieron sus obras sobre ceremonias protocolares hace ya varias décadas, poca importancia parecía tener el significado de las reglas esenciales del comportamiento diplomático (Roosen, 1980). Cabe mencionar que si bien hubo historiadores de mayor solidez científica, que estudiaron las ceremonias diplomáticas con más seriedad, sus conclusiones pueden resultar poco convincentes por su superficialidad, pues no habiendo indagado en las sutilezas que se pueden entrever, simplemente dieron su veredicto descriptivo, constatando que éste o aquel modo de actuar era lo establecido para los diplomáticos, sin mayores reflexiones acerca de los por qué.

Los historiadores de nuestra era afirman que las ceremonias diplomáticas crean las condiciones aptas para establecer una línea de comunicación y de intercambio de opiniones, nuevas ideas e información acerca de los otros estados y países. Sostienen que las ceremonias son de gran utilidad para el país receptor de una visita oficial, para el anfitrión que aprovecha la ocasión para crear, mantener o mejorar su imagen de grandeza ante la mirada internacional. No se puede omitir el hecho de que estas ceremonias constituyen con frecuencia el marco en el que se toman decisiones muy relevantes para la comunidad mundial, pues son precisamente los límites del protocolo diplomático los que permiten a los agentes de la diplomacia la entrada al gabinete, la residencia, el despacho o los jardines de los hombres de estado, reyes, presidentes o jeques (Roosen, 1980), en otras palabras, al soberano de turno.

A primera vista parece que la comunidad científica en cierta manera punto reconoce la importancia del protocolo diplomático; sin embargo su punto de vista tanto con respecto al cumplimiento de las normas protocolares como a su aplicación, adquiere cada vez un matiz más negativo, pues precisamente el hecho de prestar la debida atención a los requerimientos protocolares a veces puede acarrear a los diplomáticos más inconvenientes que éxitos plausibles en su ya de por sí difícil tarea.

A pesar de cierto escepticismo o indiferencia con respecto al protocolo diplomático, historiadores, antropólogos y sociólogos últimamente han manifestado mayor interés por abordar este tema, considerando el protocolo diplomático como la etiqueta aplicable a una esfera específica. Si asentimos a esta postura científica que equipara el protocolo diplomático a la etiqueta aplicada, es imprescindible entonces hacer un inciso para explicar que el protocolo, como conjunto de reglas y normas, no es en sí mismo un fin, sino más bien una herramienta que sirve al propósito de intercambiar información, puesto que todo acto protocolar es al mismo tiempo un acto comunicador (Jiménez, 2007).

Cuando en el proceso de comunicación se busca formular un mensaje que debe ser luego transmitido, se requiere el uso de un código. En este caso es de vital importancia la adecuación del mensaje al entorno comunicativo. Por ello, el protocolo diplomático y su desarrollo o evolución es científicamente analizable bajo el prisma comunicativo, especialmente en este momento en el que un enfoque de este tipo es prácticamente inexistente en la literatura actual sobre la diplomacia. 
El objetivo de este artículo es explicar la conexión entre el protocolo diplomático y el proceso de comunicación, y los factores que han tenido mayor influencia en el desarrollo del protocolo. La observancia del protocolo puede ser entendida como el uso de las formas de expresión adecuadas al momento y lugar para transmitir ideas, información y el deseo de conseguir un propósito concreto y bien definido (Jiménez, 2007).

Naturalmente, el desarrollo de la diplomacia ha requerido la elaboración de un código de comunicación común, un lenguaje con estructuras intersubjetivas de significados e interpretación de las palabras, acciones y símbolos (Jönson, C., Hall, M. 2005). En los últimos siglos anteriores a nuestro tiempo podemos evidenciar una subcultura diplomática bien diferenciada por sus pautas comunes de interpretación. Los orígenes incipientes de esta trayectoria se remontan a la Roma de fines del siglo XV (Jönson, C., Hall, M. 2005). Nuestra noción moderna de lo que es la sociedad internacional compuesta por una colección heterogénea de entidades ficticias llamadas estados, que supuestamente gozan de plena igualdad, soberanía y completa independencia, habría significado un gran 'shock' para el idealismo y el sentido común del siglo XV. Los reyes firmaban acuerdos con sus propios vasallos y los vasallos de sus vecinos. Recibían embajadas tanto de sus propios sujetos y como de los de otros soberanos. A veces incluso enviaban en retorno agentes que eran de hecho embajadores (Mattingly, G. 1988). Fue precisamente entonces cuando surgieron los primeros signos de un cuerpo diplomático organizado, que empezaba a desarrollar un sentido rudimentario de solidaridad profesional, a intercambiarse cortesías sociales, a codificar sus mutuas relaciones, e incluso a actuar con verdadero espíritu de cuerpo cuando surgían emergencias o situaciones imprevistas que ponían en juego su profesión (Eban, A. 1983). Por este motivo, para el estudio del protocolo diplomático como código común de comunicación en su formación y gradual desarrollo, el presente artículo toma como punto de partida cronológica precisamente este período, siguiendo a la vez el marco estructural que brindan los aspectos sobre la perspectiva comunicativa anteriormente mencionados, a saber: motivación y el fin de los agentes, sus aptitudes, intensidad y frecuencia de la comunicación, y el número de los agentes que participan.

Para abordar la interrelación del desarrollo del protocolo diplomático con el proceso de comunicación, a continuación se hacen algunas consideraciones que nos delimitan el marco teórico de este análisis.

\section{Perspectiva teórica sobre las posibilidades del protocolo diplomático}

Un estudio más acertado del protocolo diplomático bajo el prisma de la comunicación requiere enmarcarlo en el proceso de comunicación, y para esto es preciso delinear algunos de los diferentes modelos sobre este concepto y eventualmente optar por uno de ellos.

Siguiendo las afirmaciones de M. De Fleur (1975) sobre el proceso de comunicación, podemos ilustrar este proceso como un fenómeno consistente, de cierta continuidad y uniformidad: existe un transmisor que tiene como fin transmitir a un receptor cierta información, el transmisor la codifica (crea un mensaje), la envía, el receptor la recibe y decodifica, envía su reacción de retorno (en inglés, el bien conocido y empleado término "feedback").

Tal concepto de comunicación pone énfasis en la necesidad de un código común para asegurar una comunicación eficaz e inequívoca. Esta afinidad de código brinda al transmisor la posibilidad de codificar información de tal manera que el receptor al decodificar el mensaje recibido obtenga la máxima información, es decir lo más fidedigna posible al mensaje original enviado por el transmisor. Sin embargo este modelo puede resultar insuficiente, pues parece reducir la comunicación a un mero proceso de codificación-decodificación e intercambio de mensajes con los que los agentes persiguen el fin de ejercer una cierta influencia en el receptor de la información. Cabe aquí recurrir al aporte de Shramm (1973) sobre la relevancia de la relación existente entre los agentes, o a lo que Rogers y Kincaid (1981) afirman sobre la mutua comprensión o bagaje común que poseen los participantes en el proceso comunicativo.

Por tanto, si entendemos la comunicación como intercambio de información entre sujetos o agentes, la eficacia de este proceso puede ser entonces medida en función del grado de la mutua 
comprensión alcanzada, o el haber llegado a un entendimiento afín para ambos agentes. Tener un código común evita el ruido de fondo e interferencias que suelen darse en la fase de decodificación.

En la comunicación humana el significado se adquiere cuando los individuos siguen las reglas del lenguaje (Heath \& Bryant, 2000, pp-91).Por lo tanto, desde la perspectiva comunicativa, el protocolo diplomático ser considerado código unívoco que permite una comunicación eficaz.

Se puede afirmar que regirse por reglas comunes permite reducir la incertidumbre o ambigüedad condicionada por la diversidad y/o variedad; estas reglas refuerzan además la precisión y la eficacia de la comunicación. En este caso, cuando el objetivo de la comunicación es la comprensión recíproca, cobra mayor relevancia de un código común, que lógicamente debería caracterizarse por su univocidad y facilidad de uso. Precisamente por ello cabe preguntarse por qué, en el caso de la comunicación diplomática se busca la comprensión recíproca, empleando un código común (el protocolo diplomático) con reglas tan complicadas y sutiles, cuya observancia hace del proceso de comunicación un fenómeno tan sofisticado y poco natural. Si las reglas fueran menos numerosas y más sencillas, el objetivo a alcanzar sería aparentemente mucho más asequible.

Este modelo conceptual del proceso comunicativo tiene también sus falencias para responder esta pregunta tan evidente. La comunicación humana presenta una complejidad mayor en la elaboración del mensaje, tanto en su etapa de codificación, como en su posterior decodificación por dar a cada símbolo un significado correspondiente. Por eso, aunque se realizara un análisis rudimentario y elemental de de la comunicación interpersonal, estos conceptos no serían suficientes. Dar Schramm (1954) hace hincapié en la importancia del agente comunicativo introduciendo en el modelo de proceso de comunicación lo que él llama ,campo de experiencia (en inglés "field of experience"), con lo que hace referencia a las creencias, valores, experiencias y significados aprendidos ya sea por el individuo mismo o por un grupo. El modelo de comunicación ofrecido por Tubbs (1983) plantea que los significados de los signos no se encuentran en los signos, sino en nosotros. En el proceso de comunicación emisor y receptor no se limitan pasivamente a enviar y recibir; el bagaje de experiencias personales, los conocimientos previos, las convicciones, creencias y aptitudes personales juegan un papel de gran relevancia. Los mensajes externos y estímulos internos pasan por el filtro de la experiencia individual, de las posibles limitaciones léxicas, de diferencias semánticas, y significados atribuidos a los signos no verbales, etc. (Tubbs, Moss; 1983). El grado de avenencia de los campo de experiencia plantea la cuestión del ruido semántico, es decir, las posibles interpretaciones erróneas del mensaje recibido que pueden ser fruto de la diferencia de experiencias. Por lo tanto, no podemos hablar de código de comunicación como si se tratara de una realidad puramente objetiva, hemos de contemplarlo también bajo el prisma subjetivo del agente comunicativo, o sea del sujeto activo en la comunicación. En este marco, la interpretación del mensaje gana en importancia con respecto a la mera decodificación del mismo. Es por eso que al tratar sobre el proceso de comunicación es fundamental valorar también las peculiaridades de los agentes que en él toman parte activa. Sin embargo, la relevancia del agente comunicativo no se limita a su campo de experiencia y sus filtros.

Según Sperber y Wilson (1986), la codificación del mensaje incluye no solo los significados ya presentes en el código, sino también los objetivos que persiguen los agentes que toman parte en el proceso de comunicación. Un comunicador no se limita a codificar su mensaje en una señal que luego será decodificada por su audiencia (o público receptor) utilizando una copia idéntica al código. Un comunicador proporciona pruebas de la intención que tiene de transmitir un significado determinado, que es inferido por la audiencia en base a las pruebas proporcionadas. Dichos autores afirman que todo comunicador entra en el juego comunicativo provisto de objetivos a dos niveles: el objetivo informativo (el deseo de que el receptor adquiera determinada información a mediante la decodificación del mensaje que se le envía) y un objetivo comunicativo llamado también secundario (para el cual se elabora un mensaje afín). No seguiremos esta teoría al pie de la letra para nuestro estudio, ni analizaremos cómo y por qué el receptor comprende las intenciones del emisor. Nuestro enfoque se centra más bien en 
entendimiento que se da del proceso comunicativo y que se ve enriquecido por el uso de un código concreto; también abordamos la cuestión de la distinción de un fin secundario para la transmisión de un contenido más complejo y no tan evidentes.

Partir de este marco conceptual nos permite llegar a un análisis más preciso de la comunicación diplomática y a la formación y desarrollo del protocolo diplomático como código de comunicación.

Para estudiar el protocolo desde la perspectiva de la comunicación, se pueden distinguir diversos aspectos:

- La motivación y el fin secundario que persiguen los agentes que toman parte en el proceso de comunicación;

- Las características particulares de los agentes;

- La intensidad (frecuencia) de la comunicación y el número de los agentes que participan.

En primer lugar es menester mencionar que todo intercambio de información, como cualquier otro acto humano voluntario, es intencional, es decir que el sujeto obra con un fin determinado. Los agentes del proceso de comunicación pueden actuar movidos por diferentes motivos o con diferentes fines, lo cual evidentemente ejercerá cierta influencia tanto en el proceso en sí como en las peculiaridades del código en elaboración. Son precisamente estas características específicas las que facilitan la consecución del fin secundario ya mencionado.

\section{Doble fin de los agentes en el proceso de comunicación}

Como se mencionó anteriormente, siguiendo las ideas sobre el proceso de comunicación presentado por Sperber y Wilson (1986), en toda interacción comunicativa, el emisor del mensaje persigue a la vez dos fines, uno primario y otro secundario. Entendemos por fin primario el objetivo de transmitir un contenido concreto (para que el receptor se entere de algo, adquiera cierta información al decodificar el mensaje o texto). El fin secundario es ejercer influencia sobre el receptor de modo que éste tome una decisión, es decir motivarlo a actuar bajo la influencia del contenido del mensaje. En el fin secundario yace el significado sutil y cuasi-oculto de una regla. Se dan unas determinadas condiciones en las que las reglas de protocolo se van formando y estableciendo; es aquí y de esta manera como el fin secundario- o el significado segundo de una u otra regla protocolar- adquiere un sentido claro y comprensible. Sin embargo, con el correr del tiempo, las circunstancias cambian y sólo permanece la regla vaciada de contexto original en el que nació y que motivó su formación, contexto que proveía de explicación detallada de dicha regla. Valga de sencillo ejemplo el uso de guantes y el saludo con apretón de manos quitándose los guantes en la Edad Media, cuando era frecuente envenenar al enemigo a través del contacto físico. El hecho de que dos caballeros se saludaran con las manos limpias y despojadas de guantes era no solamente un acto de cortesía y simple saludo, sino que en ese contexto temporal también expresaba un segundo objetivo de no agresión, como si un caballero dijera al otro: "No tengo nada contra ti, puedes fiarte de mí, no tengo intenciones ocultas, etc.". Una vez cambiadas las circunstancias históricas, parece ya no haber motivos ni causas que dicten esa precaución en el apretón de manos sin guantes, pero la costumbre sigue reglamentada como uso protocolar. Se puede decir entonces que recurriendo a las reglas del protocolo diplomático, la persona no se limita a aplicar el comportamiento adecuado que dictan las reglas (fin primario), sino que al mismo tiempo sigue otro fin. $\mathrm{Si}$ queremos valorar $\mathrm{y}$ entender cuál es este fin secundario que motiva su actuar, es preciso mirar a fondo en el contexto en que se han ido formando las reglas y normas protocolares, Pero antes es menester analizar la situación comunicativa en sí misma.

\subsection{Incertidumbre y ambigüedad de la situación comunicativa y su reducción.}


Al considerar el origen y desarrollo del protocolo y las ceremonias protocolares, Der Derian (2001), hace hincapié en la importancia del contexto y la incertidumbre o ambigüedad propias de las situaciones comunicativas.

Por naturaleza, la persona en todo su obrar quiere lograr o mantener una cierta seguridad, un marco de certidumbre que delimite su 'zona de confort', en la que se siente seguro y libre para moverse, expresarse y actuar. Ante cualquier síntoma de incertidumbre y falta de domino de la situación, la reacción natural será la de intentar emplear todos los medios a su alcance para reducir dicha incertidumbre, e incluso evitar todo tipo ambigüedad que pueda ser provocada por situaciones incómodas e imprevistas. Dado un fenómeno, evento o hecho desconocido que no nos permite de antemano predecir o prever las causas o motivos del comportamiento de los demás, ni cómo se desenvolverán las cosas dada tal o cual reacción, la persona experimenta incertidumbre y dificultad para desempeñarse con éxito. Los antropólogos definen el ritual como una forma especial de comunicación interpersonal, haciendo hincapié en el hecho de que los rituales vienen en auxilio de la comprensión mutua, de una interpretación común libre de la ambigüedad a la que estarían expuestos los agentes comunicativos en situaciones en que la falta una adecuada señalización (sistema de signos) y bagaje común para la interpretación podría ser catastrófica (Bell, C. 1992). Esto realza la importancia del rito.

Si bien se podría admitir que en la época actual los rituales y ceremonias han perdido su auge o relevancia original y se limita su función a crear una base común para asegurar una atmósfera o contexto positivo para los agentes, también se ha de decir que, desde una perspectiva histórica, las ceremonias y rituales son han sido importantes, en cuanto que regulaban los desplazamientos a través de las fronteras o delimitaciones políticas y sociales. Der Derian (2001) afirma que en el período inicial de formación de la diplomacia - y junto con ella de manera inseparable siempre se ha ido desarrollando el protocolo diplomático- el cruce de fronteras o límites territoriales de un estado a otro era semejante a la transición que experimente una persona cuando pasa de la infancia a la edad adulta, el soltero a su nuevo estado de casado, el vivo a difunto. Esto se puede asociar tanto con la carencia de información y conocimientos acerca del país extranjero y sus habitantes, con las reglas y normas que rigen su comportamiento, como con la ambigüedad de dichas reglas y normas.

Si se considera la ambigüedad e incertidumbre de una situación desde la perspectiva de la comunicación, conviene mencionar que dicha ambigüedad está condicionada tanto por la incapacidad para reconocer, detectar e interpretar los mensajes que se envían y el entorno en que estos tienen lugar, así como por la carencia de certidumbre para interpretar adecuadamente los comportamientos e intervenciones verbales de uno y otro agente comunicativo. Se puede afirmar que en este caso, los agentes comunicativos poseen códigos diferentes para decodificar la información recibida del entorno en que se desenvuelve la comunicación. La única manera de reducir al máximo la ambigüedad e incertidumbre sería entonces la adquisición de un código unificado y sencillo, común a todos los agentes. Se trata entonces de un comportamiento que conlleva un significado simbólico, una especie de esquema. A mayor ambigüedad e incertidumbre en una situación, mayor necesidad de esquema, de algo que sea para todos comprensible unívocamente. Este tipo de esquemas de comportamiento o de conductas colectivas estereotipadas son lo que los antropólogos culturales convienen en llamar rituales (Boyer, P. Liénard, P. 2006). Por otra parte, los científicos además de analizar las funciones de los rituales, cada vez con más frecuencia enfocan su atención en el contenido comunicativo de los mismos (Bell, C.1977).

La diplomacia, por ser un ámbito de especial sensibilidad, requiere por tanto la adopción y aplicación de un código común y claro, que no precise de una comprensión gradual, sino inmediata y univoca. El comportamiento ritualizado propio de la comunicación diplomática debe su aparición al hecho mismo de la incertidumbre experimentada por los agentes participantes en una situación comunicativa que les supone entrar en una escena a la que cada uno llega con un bagaje posiblemente muy distinto de intereses, convicciones, disposiciones y marcos culturales, lo cual inevitablemente condicionará su desempeño. Es así que la reducción de la incertidumbre puede entenderse como uno de los objetivos de la comunicación que llevó a 
la formación del protocolo diplomático en su calidad de código de comunicación, y que tuvo gran influencia en la ceremonialidad del mismo.

No por mera casualidad a lo largo de la historia de la humanidad, se han ido creando e introduciendo los más variados rituales sociales que facilitan la comunicación interpersonal en la gran diversidad de situaciones más o menos complicadas. Puede decirse que un ritual es la salvaguarda contra la necesidad perentoria de tener que elegir u optar por el comportamiento adecuado en tal o cual situación, siempre con el riesgo de no acertar. Además, los rituales aseguran un mínimo común, es decir una base para subsiguientes situaciones comunicativas. En este contexto, los actos ritualizados pueden ser considerados no solo como un medio para reducir la incertidumbre y tantear las posibles jugadas del otro participante, sino también como una herramienta que permite crear y reforzar una base mínima común sobre la cual los agentes comunicativos puedan moverse con mayor ductilidad y precisión.

Edelman (1969) afirma que la variedad de ceremonias es un fenómeno habitual en la vida social, puesto que todos, estemos donde estemos, nos adherimos a principios establecidos de conducta apropiada para cada situación, es decir, nos atenemos a ciertas reglas comunes de etiqueta aplicables al comportamiento social en general. Formalidad, persistencia y repetición pueden ser consideradas estrategias comunes de ritualización (Bell, C. 1992).

Generalmente, la comunicación diplomática protocolar se ha ido formando a lo largo de muchos años de práctica y usanza, reforzadas por la adopción y aceptación de normas de expresión y comportamiento a las que los participantes se atienen.

La carencia de información que se podía acusar en épocas anteriores como factor de incertidumbre y ambigüedad en las situaciones comunicativas encuentra su remedio en el rápido desarrollo tecnológico que ha ido en incremento desde la segunda mitad del siglo XX. Esto facilitó la comunicación, haciéndola no solo más y más intensa, sino también permitiendo acceder de manera casi inmediata a conocimientos de primera necesidad, a datos que se pueden almacenar con gran facilidad, para su uso posterior cuando esto se requiera. A su vez ha cumplido otra función: reducir la potencial incertidumbre y ambigüedad de las situaciones comunicativas, y restar importancia a la hasta entonces abundancia y complejidad de los rituales y ceremonias. Los conocimientos adquiridos preservan y refuerzan la capacidad de decodificar adecuadamente y de comprender mensajes recibidos en un entorno desconocido. La creciente abundancia de información acerca de los demás y de su diversidad es correlativa al incremento del arsenal de códigos disponibles. Cada vez es mayor la probabilidad de que el receptor será capaz de decodificar el mensaje y recibir información más y más fidedigna a la original enviada por el transmisor.

De esta manera el ritual ha ido perdiendo su doble función para, cada vez con mayor frecuencia, convertirse solo y prácticamente en un medio que asegure el necesario mínimo común.

Sin embargo, aunque la comunicación diplomática cuente hoy con el código común - el protocolo diplomático del que venimos hablando- se sigue percibiendo cierto grado de incertidumbre y ambigüedad en las situaciones comunicativas, debido a la diversidad cultural. Si bien el contexto de la comunicación diplomática hasta la primera mitad del siglo XX se delimitaba prácticamente dentro del mundo occidental, abarcando también otras culturas afines, aunque fuera de este marco geográfico, desde mediados del siglo XX, a la arena diplomática acceden cada vez más países y estados nuevos, cada uno con sus propias características culturales, algunas bien distintas con respecto al hasta ahora familiar contexto occidental. Esto naturalmente motiva la necesidad de garantizar la mutua comprensión y univocidad en un entorno multicultural que respete a la vez la singularidad de los diversos agentes comunicativos y sus raíces culturales. Los agentes diplomáticos comparten un código común, pero al mismo tiempo son miembros y representantes de culturas distintas que tienen a la sazón un código propio. Cabe acotar que cuando en la situación comunicativa intervienen miembros de diferentes culturas nacionales, y que por tanto traen sus propios códigos, los signos verbales (palabras) están sujetos a diversa interpretación y esto puede producir significados bien distintos (Jönson, C., Hall, M. 2003), pues los referentes están teñidos precisamente por la mencionada diversidad cultural, aun cuando lingüísticamente se trate de los mismos signos. 
Los científicos generalmente que se pronuncian sobre el protocolo hacen referencia a sus tradiciones occidentales. Sin embargo, una mirada exploradora con un radio de mayor amplitud brindaría la oportunidad de observar reglas de comportamiento diplomático fundamentadas en una base totalmente diferente. En los países árabes el protocolo asienta sus fundamentos en la religión y en el patrimonio histórico-cultural. En otros países de mayoría musulmana la religión constituye la base primordial (Álvarez Gómez, 2007). Dejando a un lado el contexto geográfico y cultural específico, el protocolo diplomático determina un conjunto de formas de comportamiento verbal y no verbal que se ha ido estableciendo de común acuerdo con la usanza y que posibilita la reducción de la incertidumbre y ambigüedad propias de un entorno condicionado por la diversidad cultural. El lenguaje diplomático moderno presenta un sinfín de frases estandarizadas y cautelosos giros y eufemismos. En resumen, cada era parece haber contado con su propio conjunto de frases rituales que eran correctamente interpretadas entre los agentes diplomáticos y soberanos, lo cual les permitía comunicar las más desagradables noticias o enunciar puntos de vista contrarios con una buena dosis de tacto y cortesía ( Jönson, C., Hall, M., 2005).

\subsection{Demostración de pertenencia a un determinado grupo o estrato}

Los estudiosos de la psicología social sostienen que, sea cual fuere el grupo o el estrato, toda entidad social pretende autodefinirse y delimitarse, encontrar y poner de relieve las características distintivas que une a sus miembros y los diferencia de otros, las peculiaridades que los separa del resto de la sociedad. Los grupos cerrados que desean mantener su exclusividad se caracterizan por minimizar la expresividad individual de sus miembros y realzan la importancia de las reglas de comportamiento (Berne, 1975). Autodefinirse y diferenciarse de los demás es un fin que las personas persiguen haciendo uso de signos externos, de la vestimenta, determinados comportamientos, maneras de hablar, etc. El escritor ruso Doblatov (1985) al hablar acerca de la jerga de los criminales explica que para un criminal, el lenguaje cumple las funciones de autodefinición e identificación con su grupo social, que para los demás ciudadanos vienen a darse con los accesorios 'civiles', es decir: el traje importado, el estilo de peinado, los zapatos, la corbata y las gafas. Y por si esto no bastara, también se recurre al dinero, la posición social, las condecoraciones y medallas. De mayor relevancia "entre los de nuestro bando" (entre criminales) es el lenguaje que hace las veces de arma, de defensa, y manifiesta cierta reputación y estatus, tanto como lo haría la fuerza física. En otras palabras, cada grupo o estrato declara sus propias reglas de pertenencia, y así lo era también en la Edad Media, período de gran desarrollo en lo que respecta a reglas de comportamiento.

El protocolo diplomático actual aun cuenta con innumerables ceremonias, sin embargo estas gozaron de su verdadero auge en la Edad Media El comportamiento refinado de la alta sociedad feudal contrastaba diametralmente con la conducta franca de la plebe. Según Dizelbacher (1998), difícil es imaginar un contraste mayor que el que se daba entre las maneras refinadas de los nobles de los siglos XVI-XVII con respecto al comportamiento plebeyo. Evidentemente, las formas de comunicación de la gente sencilla y franca del campo eran lo más opuesto a la altamente sofisticada comunicación de los cortesanos. La etiqueta palaciega acentuaba la exclusividad de los aristócratas y su superioridad social, sirviendo así como salvaguarda de la nobleza. Durante la época de apogeo del régimen monárquico se decía que las normas de etiqueta unían a las personas con un vínculo más fuerte que el de las leyes.

En aquel entonces el pomposo ceremonial subrayaba la firmeza del poder de los monarcas, convirtiéndolos en personas excepcionales y exclusivas, inalcanzables para el resto de los seres mortales y ordinarios. Sin embargo, el protocolo se caracteriza no sólo por la abundancia de ceremonias, sino también por su refinamiento, cierta presuntuosidad y algo de amaneramiento. Los históricos coinciden en establecer el punto de origen de este comportamiento refinado en las estancias de la alta burguesía Europea del Medioevo tardío, cuando los señores feudales se reunían alrededor del monarca, quien ejercía de centro del poder en su estado, y desafiaban a los guerreros poderosos esgrimiéndose con un comportamiento de estudiada cortesía (Der Derian, J. 2001). Este cambio cualitativo es estudiado por diversos autores y cada uno argumenta su 
postura partiendo de distintas causas. Unos prestan mayor atención a la peculiaridad de una u otra casa burguesa o familia noble, sosteniendo que en cada propiedad de la nobleza se encuentra un elevado número de personas que están integradas, identificadas y tan hechas al ambiente en que se desempeñan que casi parecen formar parte del edificio que habitan, de los muros que los rodean. Cada uno de ellos, al igual que las diferentes habitaciones, están distribuidos en distintos niveles, guardando determinadas distancias; sus funciones están claramente estipuladas y explícitamente delineadas (Canetti, 2003). El comportamiento y porte de los señores nobles se impone ante los demás como un ejemplo para los subordinados. Por otra parte, las mansiones señoriales del Medioevo eran consideradas lugar donde todos querían acuñar fortuna y reafirmar su estatus. Y para lograr estos objetivos era preciso primero ganarse el favor del señor de la nobleza, de sus allegados y servidores. El medio principal para este fin era la cortesía, el comportamiento refinado y estudiado, dictaminado por un sinfín de reglas (Dizelbacher, 1998). A mayor rango correspondía un número más elevado de normas a aprender y aplicar (Elias, 2004).

El comportamiento meticulosamente estudiado y refinado constituía lo más opuesto a una conducta totalmente franca, aunque esta última pudiera ser regulada por ciertos rituales también. La cortesía (courtoisie) demostraba retracción y distanciamiento de las relaciones vasallas y belicosas, así como el paso de una lucha abierta por el poder bélico a una batalla enmascarada por el prestigio y dominio (Dizelbacher, 1998). La intención de negar el orden vigente hasta el momento y de instaurar uno diferente llevó a establecer unas normas para regular la comunicación, pero estas acabaron siendo más complicadas aun que aquellas que se querían abolir por su rebuscamiento. La comunicación que ya de por sí estaba cargada de simbolismo adquirió matices aun más sutiles. En palabras de Van Wicquefort (1981), por tener que atenerse a un protocolo de la nobleza medieval cada vez más complejo, las ceremonias y homenajes se consideraban los deberes principales de la embajada. Las palabras más utilizadas en la comunicación diplomática del siglo XVII eran "gloria" y "honor". El embajador tenía la obligación de proteger el buen nombre de su señor (el soberano, monarca, príncipe, etc.) de tal manera que nadie ni nada pudieran mancharlo o herir su reputación, pues un embajador siempre actuaba en representación de grandeza y majestad de su señor. Pero no eran solamente los monarcas quienes se preocupaban de la deferencia que los demás les debían por su rango y estatus. Este era también el objetivo que perseguían los gobernantes de las repúblicas modernas que empezaban a surgir. Estos soberanos no perdían ocasión de, ya sea por escrito o personalmente de palabra, recordar a los poderosos e influyentes señores de la noblezas que ellos también estaban en excelentes relaciones con otros soberanos.

La expansión y desarrollo de las relaciones diplomáticas coincidieron históricamente con el afianzamiento del absolutismo; sin embargo, rara vez los soberanos de este período llegaron a encontrarse frente a frente como lo hacen ahora los jefes de estado. Los monarcas y gobernantes se desplazaban a tierras lejanas con muy poca frecuencia, siendo más la usanza el enviar un representante en calidad de embajador. Así los encuentros diplomáticos tenían lugar entre el representante del soberano de un estado y el monarca del otro país o estado en cuestión, o la más de las veces entre los embajadores que actuaban en nombre de sus respectivos soberanos, mientras estos últimos permanecían en sus dominios. Durante el ritual, la persona expresa su respeto y favor a la persona honrada o a la que haga sus veces en esa ocasión" (Goffman, 1971, 62). Por ello, se puede afirmar que el respeto y honor debidos al soberano de un país extranjero había de ser igual al que se manifestaba a su enviado diplomático; de lo contrario, toda falta de condescendencia con el representante sería entendida como una ofensa a la persona del soberano a quien el diplomático representaba.

Si se tiene por finalidad demostrar la conformidad con unos u otros estándares, se ha de prestar debida atención a la forma en que se envía el mensaje y a los más ínfimos matices. La pertenencia a uno u otro grupo social indica una infinidad de signos históricamente visibles, tales como la vestimenta, modos de comportarse, la elección de situaciones y ocasiones en las que se tomara parte, etc. 
Desde el renacimiento hasta la Revolución francesa las maneras refinadas de comportamiento constituían un elemento esencial de buena convivencia; eran consideradas una característica ineludible en el currículum de toda persona culta. Su relevancia en la sociedad de los siglos XVI-XVII llenó las páginas de numerosos libros sobre buenos modales y etiqueta que se proponían dar consejos sobre la manera debida de comportarse según el estrato social o rango al que cada uno pertenezca. Estos libros dedicaban parte de su contenido al tratado de principios morales, buenas maneras, formación del carácter, el arte del saber estar en la sociedad y convivir en armonía. Se incluían también lecciones para aprender a bailar con gracia y elegancia, exhortaciones y amonestaciones acerca de la sobriedad y templanza en el dominio de las pasiones, reglas de comportamiento en la mesa y advertencias sobre la necesidad de la honestidad y la justicia (Curtin, 1985).

Cabe preguntarse por qué en ese entonces se adoptaron tantas reglas que dieron legitimidad al refinamiento y asentaron cierta artificiosidad en la comunicación interpersonal y por qué más tarde otros se ensañaron para abolirlas. Esto puede explicarse teniendo en cuenta que también los representantes mismos de la nobleza perseguían su propio fin: definirse y delimitar su círculo social restringido para los no pertenecientes a su casta (Der Derian, 2001). Los estudiosos del tema convienen en afirmar que comenzó a surgir en los opositores y los rebeldes contra el orden vigente una verdadera necesidad de cuestionarlo todo, empezando por las personas para acabar con cualquier símbolo, regla u objeto que trajera a colación las reglas de dicho orden. Cuando se asume una postura reaccionaria, los individuos tienden a rechazar de llano lo que hasta entonces regía su conducta, simplemente por el hecho de que estos principios pertenecen a las estructuras o marcos contra los cuales ahora se entra en batalla. (Cabanes, Nass, 1988). Dada estas circunstancias el propósito de la comunicación se centra en satisfacer los requisitos establecidos y alcanzar el favor o el buen parecer del interlocutor.

Una clara demostración de que la etiqueta cumplía la función de definir y delimitar la pertenencia son las medidas tomadas para rechazar la aristocracia impugnando sus normas de comportamiento. Hay numerosos ejemplos que sirven para la ilustrar como las normas de comportamiento demuestran la pertenencia a un estrato social exclusivo o a una elite. A modo ejemplo se ha de mencionar el intento de los revolucionarios- en particular los franceses- que se habían propuesto cambiar el protocolo diplomático. Este objetivo es correlativo con la rebelión contra el régimen vigente y la desigualdad. La revolución iba dirigida a afianzar el triple principio de una nueva existencia bajo el slogan "libertad, igualdad, fraternidad". Los revolucionarios pretendían hacer accesible a todo el pueblo lo que hasta entonces era privilegio de unos pocos. Cabanes y Nass (1988) afirman que cuando tiene lugar una agitación social, se establece una particular cosmovisión, sola y propiamente característica a estos momentos: Homo homini lupus est. Y es precisamente en este periodo cuando surge la necesidad imperiosa de dar persecución a todo, empezando con las personas hasta acabar con los símbolos y las cosas más materiales. Los individuos rechazan los principios mismos por los cuales hasta entonces ser regían y ni se les ocurre pensar en las consecuencias que puedan llegar a tener tal ensañamiento contra el orden establecido y el arrasar con todo lo que está en pie. Se destruye por destruir, se ataca por atacar, por el mero hecho de acabar con todo lo que traiga reminiscencias del régimen anterior, pues contra él se lucha vehementemente. Los objetos que se quieren destruir hacen referencia directa al poder real (mausoleos, escudos de armas en los edificios, etc.). La destrucción revolucionaria es simple y llanamente un atentado contra todos los límites impuestos por otro. El objetivo es abolirlo todo: ceremonias, rituales, y todo aquello que suponga marcos y límites, lo que parezca amenazador e insoportable a los representantes de la nueva ideología. (Canetti, 2003). Es así que, por ejemplo, los cambios revolucionarios no perdonaron ni siquiera el uso del lenguaje. El tratamiento con el uso del tú se hizo obligatorio a todos y así debían dirigirse unos a otros, ya fueran ciudadanos de quince años o un hombre adulto dirigiéndose a una dama, ya fuera un sirviente quien hablara con su superior. Las cartas dirigidas al ministro iban encabezadas con las palabras "al ciudadano ministro" y a continuación en todo el texto se empleaba el pronombre tú. (Cabanes, Nass, 1988). Los revolucionarios rusos procedieron de manera similar, exigiendo el uso de camarada (товарищ- amigo/a) para dirigirse 
a cualquier persona. Así, los mismos revolucionarios que buscaban abolir la aristocracia, demostraban su pertenencia a una "nueva elite" haciendo uso de las mismas formas, pero rellenándolas con un contenido nuevo. Como representantes de la República en el extranjero el gobierno revolucionario francés designó ciudadanos de confianza, que no sucumbieran a la tentación del ambiente aristocrático. Según dictaba el nuevo régimen, el comportamiento del representante electo debía guardar conformidad con la República. Esto conllevaba una cautelosa conducta para no caer en el error de seguir las normas establecidas por la diplomacia tradicional universalmente aceptada entonces (Frey, 1993). El patriota Sémonville, entonces representante de Francia en Constantinopla fue severamente amonestado por su comportamiento de embajador demasiado conforme al antiguo régimen, pues en sus viajes se desplazaba acompañado de una cohorte numerosa y pomposa. Los revolucionarios explícitamente rechazaron los rituales públicos preparados con meticulosidad enfermiza que no hacían más que encandilar y despertar viejos sentimientos enraizados en el régimen monárquico, ensalzando y exaltando el abominable antiguo régimen (Mayer, A. 1981). Los franceses que participaron en el Congreso de Rastatt se negaron a rebajarse y atenerse a la etiqueta tradicional. Iban ataviados con chaquetas y pantalones, en lugar de llevar el tradicional traje diplomático de la época. Y caminaban compulsivamente a grandes pasos que parecían más bien zancadas, con las que venían a reemplazar el andar elegante propio de un diplomático (Frey, 1993). La confrontación de puntos de miras opuestos se hacía aún más evidente cuando se daban cita las dos batientes, es decir, los revolucionarios y el resto del mundo, pues cada uno se consideraba defensor de su legítimo sistema, enarbolando el arma de su comportamiento. A modo de idea sumaria sobre el contexto en que se formaron diversas reglas de comportamiento, podemos decir que el estrato social de la nobleza siempre busco distinguirse del resto de los ciudadanos ordinarios, y lo hizo desarrollando una manera particular de comportarse propia a su elite. Desde el punto de vista evolutivo, se puede observar que en el periodo de formación del protocolo diplomático la autodefinición y demarcación de pertenencia a un determinado estrato social era un fin claramente deseado.

En la actualidad se procura más bien la afiliación a un cierto grupo social, pero no con tan alto grado de sofisticación y amaneramiento.

\section{Características particulares de los agentes comunicativos}

Si continuamos estudiando el proceso de comunicación y su relación con el desarrollo del protocolo diplomático, otro aspecto que merece consideración es la capacidad de los agentes comunicativos para expresar sus ideas, y para comprender los mensajes que a ellos se les transmite. Los investigadores del tema asocian la formación de las normas del protocolo diplomático con la propagación por Europa de las normas de etiqueta que dictaminaban la forma de comunicación interpersonal. El bajo o inexistente nivel de alfabetización de la gente de la baja Edad Media demarcó la profusión de la comunicación no verbal y simbólica. La ética de las cruzadas tuvo gran impacto en las normas que regulaban la conducta de los señores feudales del siglo XI y sus súbditos (Duby, 2004). Los caballeros no aprendían a leer ni escribir; se pensaba que el saber y la ciencia echarían a perder la los valientes. El valor principal de este estrato social era la honra y por ella se luchaba y hasta se moría; la honra y el honor eran la fianza que se dejaba cual joya empeñada en los concursos de destreza guerrera y competencias de caballerosidad, característicos de la vida feudal. Los historiadores sostienen que los caballeros no se distinguían precisamente por sus maneras refinadas; la cultura y conducta típica del caballero feudal totalmente ajena a la alfabetización (en lo que se refiere a la educación formal en las letras, en la expresión escrita), se fundamentaba en la palabra hablada y en la imagen, las cuales sirvieron de base a la ritualización del comportamiento ordinario. En la Edad Media la comunicación no verbal jugó así un papel de gran relevancia por el empleo de símbolos y gestos. Así se expresa Tomas de Aquino refiriéndose al lenguaje gestual: "non sunt ridiculosae gesticulationes, fiunt enim ad aliquid repraesentandum "(los gestos no son en absoluto ridículos, si se usan es con el claro objetivo de expresar algo concreto. Y sobre esto se 
puede encontrar gran variedad de ejemplos. Cuando un caballero se convertía en dueño de un feudo, la toma de bandera en sus manos o el elevar su mano apretando un puñado de tierra eran gestos que adquirían un significado simbólico (Duby, 2004). También se puede mencionar en este contexto el beso con que se sellaba un contrato, un tratado de paz o de reconciliación, beso que en otras ocasiones simbolizaba comunidad litúrgica, o expresión de humildad e intenciones pacificas (Dizelbacher, 1998). Los signos más importantes que un soberano utilizaba para ostentar su poder real eran la corona de rey, el cetro, el globo terráqueo y la "espada santa". Similar función se le atribuía a los anillos que, como hasta ahora, se consideraban un signo visible de amor y significaban además el poder de quien lo llevaba (Dizelbacher, 1998). En los siglos XIII-XV los guantes dejaron de ser un mero accesorio de la vestimenta para adquirir además entre otros significados, el valor de poder y grandeza: si al pasar por la aldea el soberano dejaba caer su guante cual regalo en manos de algún aldeano, este era investido del derecho a abrir tienda en el mercado y convertirse en mercader. El guante simbolizaba también una misión de importancia confiada a un caballero que a su vez podía pasársela a otro; y hay más: si un valiente arrojaba su guante a los pies de otro caballero, esto implicaba reto a duelo; las damas obsequiaban su guante a su elegido (Kuznecov, 2002). Un simbolismo parecido podría aplicarse a otros elementos y detalles de los trajes y accesorios de la época.

Con todo lo dicho se puede afirmar que la limitada capacidad comunicativa de los agentes para expresar sus ideas y procesar información fue un factor decisivo en la abundante aplicación de formas no verbales de comunicación, lo cual se vio ampliamente reflejado en las reglas de etiqueta que iban tomando forma.

Actualmente los requisitos para desempeñar cargos diplomáticos están claramente estipulados y no basta con tener ciertas dotes de retórica, un sexto sentido para intuir la oportunidad o no de un comentario, o la perspicacia para elegir el comportamiento adecuado a la situación y circunstancia en que se encuentra el diplomático. Todo esto es necesario pero ha de contar con el debido aval de documentos, diplomas y certificados. La selección de candidatos a cargos diplomáticos es tarea que llevan a cabo generalmente los Ministerio de Asuntos Exteriores, que en algunos países cuentan con escuelas de diplomacia para la formación de sus representantes en el extranjero. En Argentina, por ejemplo, el Instituto del Servicio Exterior de la Nación (ISEN), dependiente del Ministerio de Relaciones Exteriores, Comercio Internacional y Culto, es el organismo único de selección, formación e incorporación de los funcionarios diplomáticos argentinos. Los futuros diplomáticos han de haber pasado por el riguroso filtro de un concurso de ingreso que consiste en varias instancias de evaluación, con exámenes escritos de Lengua Castellana, Derecho constitucional e internacional público, Principios de Economía, Historia política y económica argentina, Historia de las relaciones políticas y económicas internacionales y Teoría política. Además, son evaluados en Cultura General, y deben redactar un Ensayo sobre temas Economía internacional y Comercio Internacional. Finalmente, se presentan a un coloquio público de aptitud diplomática.

Otro ejemplo cercano culturalmente es el caso de España, uno de los primero Estados en crear una Escuela Diplomática (1942) para la formación de diplomático. Hoy en día el Ministerio de Asuntos Exteriores y Cooperación es el responsable de la selección de candidatos, quienes han de ser ciudadanos españoles, tener cumplidos los 18 años y estar en posesión de un título superior universitario (Licenciado, Arquitecto o Ingeniero) y han de pasar por varias pruebas también. Similares son los requisitos en muchos otros países, aunque las formalidades de edad, tipo de título universitario y pruebas de selección puedan variar de uno a otro.

Estos requisitos, entre otras cosas, revelan la importancia que se le da a la competencia comunicativa como capacidad retórica, lo cual contrasta ampliamente con el papel que desempeñaba la comunicación no verbal tan abundante en el período inicial de formación del protocolo diplomático. Como ya se ha explicado, esto se debía al limitado grado de alfabetización y educación formal que poseían incluso los representantes de los más altos estratos sociales, cosa ahora inaceptable en un diplomático. Una competencia comunicativa bien probada es hoy en día una aptitud esencial en la dote de todo diplomático. Jiménez (2007) afirma que la comunicación diplomática es persuasiva pues, en la mayoría de los casos, el 
propósito de la comunicación viene a ser precisamente persuadir, exaltar la relevancia de un asunto concreto, captar el interés del público, llamar la atención y dirigirla hacia un punto predeterminado, etc. Los postulados de la retórica como ámbito específico de la comunicación recalcan la importancia que adquiere la unidad de forma y contenido cuando se quiere persuadir. En otras palabras, un buen contenido ha de ser presentado con perfección. La belleza de un cuadro o la calidad de una novela yace no solo en el tema elegido, sino también en su tratamiento y modo de exposición (Sanabria, 1994). La carencia de debida atención a la forma adecuada reduce la eficacia del mensaje y puede llegar a condicionar de manera total la consecución del fin que se persigue. Si el propósito de la comunicación es persuadir y complacer, se sobreentiende que se ha de poner especial énfasis en la forma. Esto fundamenta la exhaustiva y abundante reglamentación de formas de expresión y la relevancia de las mismas, tal como están contempladas en el protocolo diplomático.

Hasta aquí se ha hecho una valoración cualitativa requerida de los agentes comunicativos, destacando la relevancia de sus características particulares, capacidades de expresión, aptitudes en el manejo de los recursos a su alcance, su conocimiento. Pasamos en la siguiente sección a un análisis cuantitativo, para referirnos al crecimiento numérico de estos agentes y la mayor frecuencia de su interacción.

\section{Creciente número de agentes comunicativos y de situaciones comunicativas}

Desde mediados del siglo XX comienza a darse una palpable intensificación de la comunicación. Las innovaciones tecnológicas han facilitado notablemente el intercambio de comunicación diplomática, pero también han supuesto un verdadero desafío a los ya arraigados usos y procedimientos diplomáticos (Jönson, C., Hall, M. 2003). Los notables progresos tecnológicos (redes de caminos, perfeccionamiento de los medios de transportes) facilitaron enormemente el movimiento en espacios de gran dimensión y la posibilidad de cubrir largas distancias que hasta el momento parecían inabarcables en espacios de tiempo relativamente cortos. Si antes los soberanos de los estados rara vez se daban cita en encuentros cara a cara, ahora este tipo de reuniones tienen lugar con una frecuencia y regularidad sin comparación. A lo largo de la historia, los encuentros personales entre los soberanos de los grandes imperios y de los posteriores estados pasaron de ser muy esporádicos y extremadamente formales a darse cita en reuniones más o menos formales, para hoy en día ser casi asuntos de ordinaria administración sobre los cuales los grandes hombres de este siglo sencillamente toman nota en su apretada agenda de trabajo. Desde el año 1960 cada vez se dieron con más frecuencia los eventos llamados reuniones "cumbre". Hoy en día apenas transcurren un par de semanas entre una reunión cumbre y otra (Jönson, C., Hall, M. 2003), tal es la creciente frecuencia de estos eventos. Y gracias a los avances técnico, los encuentros de altos mandatarios de estados y de delegaciones oficiales se han convertido en una prueba singular de protocolo diplomático ya que toda la atención se centra en la consecución de un objetivo concreto, como puede ser llegar a un acuerdo, diseminar determinada información, persuadir a los participantes, etc. Sin embargo también es cierto que estos encuentros son un reto a la capacidad ejecutiva y no solo al arte de la diplomacia, como lo expresa Jan Melissen (2002) al decir que luego de varias experiencias aleccionadoras en las controversiales reuniones cumbre de la segunda mitad de la década del 1990, es evidente que los encuentros de alto nivel suponen también un cuestionamiento que pone en tela de juicio la autoridad misma de los altos mandatarios.

La frecuencia de este tipo de reuniones y el enfoque hacia la resolución de un problema concreto dictaminan el propósito de reducir la habitual abundancia de rituales y restar formalidad a los encuentros. La informalidad empieza a ser estimada como uno de los factores que allana las posibles dificultades cuando se han de tratar asuntos delicados, permitiendo reducir la tensión natural que surge ante conflictos candentes. Aunque estos no dejen de ser una cuestión crucial, los encuentros diplomáticos pueden interpretarse como un evento de "formato libre" en el que algunos amigos pasan un rato agradable y totalmente distendidos. 
Por otro lado, la transición comenzada ya en el siglo XIX de los asuntos diplomáticos que antes se trataban en la corte o en el territorio del soberano y empezaron a trasladarse a los gabinetes gubernamentales se hace más frecuente y más evidente. Los representantes del gobierno o la autoridad vigente intervienen cada vez más en las tareas que hasta entonces eran ámbito exclusivo de los diplomáticos. Los altos funcionarios del gobierno con mayor frecuencia requieren de los enviados especiales y embajadores información vital sobre asuntos políticos y no sólo ya para demostrar interés y cierto dominio de la situación actual de su estado, sino más bien para buscar ellos mismos soluciones a las cuestiones que hasta entonces los diplomáticos consultarían directamente con su soberano, o incluso resolverían usando el poder a ellos conferido por sus soberanos. Esto en cierto modo significó un desplazamiento del diplomático hacia un segundo plano, dejándole en un papel más bien decorativo en el desempeño de sus funciones. Esto no quiere decir que los miembros del cuerpo diplomático de los siglos XX y XXI se dediquen meramente a viajar por el mundo para participar en recepciones y cocteles, y bailar un vals mientras los "verdaderos políticos" se reúnen en una sala contigua y tratan de asuntos serios, pues bailar no saben y no tienen preparación suficiente de protocolo diplomático para hacer un buen papel, ni tiempo ni ánimos para festines y banquetes. Cierto es que los diplomáticos gozaban antes de mayor libertad o poder para tomar decisiones en lugar de su soberano, quien le confiaba una determinada misión. Los embajadores y enviados - a veces plenipotenciarios- solían desempeñar sus funciones físicamente lejos de su soberano (su jefe) y por tanto, o bien debían tomar decisiones por sí mismos y luego dar cuenta de su trabajo al volver a su país o estado, o enviar un informe escrito de lo realizado hasta el momento a través de correspondencia que viajaría largas millas antes de llegar a manos del monarca, gobernador o jefe de estado en cuestión. Con suerte y buena voluntad conseguían consultarle sobre el modo más adecuado de proceder en asuntos a veces urgentes y delicados que no siempre podían esperar la vuelta de correo. Debido a la revolución digital en el campo de las técnicas de comunicación y las mejoras en los servicios de transporte, los jefes de estado en la actualidad pueden en cualquier instante ponerse en contacto con sus embajadores, o darse cita con sus representantes en cualquier punto del mundo y darles indicaciones concretas, elaborar un plan conjunto de acción inmediata para resolver uno u otro asunto. En nuestros días se puede observar cómo la comunicación diplomática y política se lleva a cabo a través de los más diversos canales; a las filas de la diplomacia se incorporan cada vez con mayor frecuencia personajes que han sido recientes figuras políticas activas, pujantes empresarios, e incluso agentes sociales, cuya preparación profesional original dista mucho de ser la diplomacia con su protocolo, y las ciencias políticas o relaciones internacionales.

La intensificación de la comunicación y la posibilidad de acceder a la información requerida de manera casi instantánea han supuesto un giro cardinal en la reducción de la incertidumbre propia de las situaciones comunicativas impredecibles. Así es como comienza a desvanecerse la necesidad de una comunicación regida por rituales. Aun más, el nivel de educación y conocimiento general del que la mayoría de la gente puede gozar, equipan al hombre actual con las herramientas necesarias para decodificar los mensajes que recibe y para procesar una creciente cantidad de información. Por todo esto, nada tiene de asombroso el hecho de que la abundancia de rituales y ceremonias que antes garantizaban la fluidez de la comunicación, ahora sean más bien un estorbo, ya que dichos rituales y refinamientos en la conducta han acabado por perder su función original y se convierten en un mero ceremonialismo, que poco a poco se va dejando de lado.

Gracias al intenso desarrollo de las tecnologías de comunicación, también los medios masivos de comunicación se han convertido en parte activa de la comunicación diplomática. Las tecnologías han dejado de ser meros canales transmisores de información. Ahora también interpretan la información que antes era su "materia prima", se puede decir que la presentan ya elaborada, filtrada y condimentada con receta propia; el mensaje que transmiten va cargado de una visión y sentido propio. Con la entrada de los medios masivos en el proceso de comunicación, la arena en que se desenvuelve el protocolo diplomático se expande. El agente de comunicación diplomática se ve envuelto en el proceso de comunicación prácticamente toda 
la jornada, ya no puede retirarse del escenario, pues la revolución digital su actuar se ha convertido en visible cotidianeidad a la que se que tiene acceso las 24 horas del día en cualquier rincón del mundo. Este devenir en cotidianeidad a su vez condiciona la simplificación de las reglas del protocolo diplomático y del incremento de las ocasiones comunicativas. Esta última sección ha presentado un análisis sobre el impacto que los avances tecnológicos han tenido en el aumento de ocasiones comunicativas y en los cambios cuantitativos y cualitativos del papel que juegan los agentes de la comunicación diplomática y política, dando así cierre a nuestro esbozo del protocolo diplomático y su desarrollo en el tiempo bajo el prisma de la comunicación. A continuación exponemos brevemente ideas conclusivas sobre el presente estudio.

\section{Conclusiones}

El protocolo diplomático juega el papel de código comunicativo en el que se contienen un sin fin de reglas formalizadas y no formalizadas, y que facilita al receptor la codificación de los mensajes de una manera más comprensible. Por ello puede ser considerado una parte inseparable del proceso de comunicación diplomática. Además, el protocolo diplomático es dinámico y no es ajeno a la influencia que en él pueden ejercer los cambios que se dan en los variables objetivos de la comunicación, sus agentes y el entorno en que ésta tiene lugar.

Cabe distinguir los siguientes objetivos de la comunicación que han ejercido notable influencia la formación del protocolo diplomático como código comunicativo:

- reducción de la incertidumbre y ambigüedad en la situación comunicativa;

- creación de un mínimo común entre los agentes que toman parte en la situación comunicativa;

- demostración de conformidad con los estándares establecidos y adquisición de favor y reconocimiento;

- persuasión.

La variabilidad del contexto comunicativo ha condicionado la sucesión y evolución de estos objetivos según fueron cobrando menor o mayor relevancia en cada período histórico, lo cual a su vez ejerció su influencia tanto en la formación misma del protocolo diplomático, como en la necesidad de introducir modificaciones, o de omitir elementos que parecían ya obsoletos o irrelevantes a las sucesivas épocas.

El desarrollo de las tecnologías de comunicación tuvo un impacto directo en la creciente diversidad y número de agentes involucrados en el proceso de comunicación, y en los nuevos espacios físicos (incluso virtuales) en que tiene lugar la comunicación diplomática. El impulso tecnológico también se hizo sentir en la intensificación de la comunicación.

El cambio sucesivo de objetivos en la comunicación y la evolución de la competencia y aptitud de los agentes comunicativos, así como el progreso y perfeccionamiento de los medios, pueden ser también contados entre los factores que han determinado y condicionado el desarrollo y evolución en el tiempo del protocolo diplomático.

Resta ahora preguntarse cuáles serán las siguientes transformaciones que sufrirá el protocolo diplomático en nuestra era, ya posterior al post-modernismo, y a qué factores se deberán los cambios que eventualmente tendrán lugar. O no.

\section{Referencias}

ÁLVAREZ GÓMEZ, María Enriqueta. (2007). El protocolo como herramienta de integración en los estados // ponencias del VIII Congreso de Protocolo en México 18-20 abril 2007 "Los retos del Protocolo, del Derecho Internacional y de las Relaciones Internacionales". Enlace en la red:

http://www.uam.mx/actividaduam/ampro/viiicpm07/El_protocolo_como herramienta de integ ración.pdf. 
BELL, C. (1977) Ritual: Perspectives and Dimensions. New York and Oxford: Oxford University Press.

BELL, C. (1992) Ritual Theory, Ritual Practice. New York and Oxford: Oxford University Press.

BERNE E. (1975) The Structure and Dynamics of Organizations and Groups. New York: Ballantine Books

BOYER P. LIÉNARD P. (2006) Why ritualized behavior? Precaution Systems and action parsing in developmental, pathological and cultural rituals. Behavioral and Brain Sciences (2006) 29, 595-650.

CANETTI, Elias. (2003). Masė ir valdžia (Las masas y el poder). Vilnius: Alma littera, 2003. $535 \mathrm{p}$.

CURTIN, Michael. (1985). A Question of Manners: Status and gender in Etiquette and Courtesy // The Journal of Modern History. Vol. 57, Nr.3. (Sep., 1985), pp. 395-423.

DANTON, Georges J. (2008). Discours civique de Danton. Paris: Echo Library, 2008. 136 p.

DE FLEUR, Melvin; BALL-ROKEACH, Sandra. (1975). Theories of Mass Communication. New York: Longman Publishing Group, 1975. 288 p.

DER DERIAN, James A. (2001). Apie diplomatiją: Vakaru susvetimejimo genealogija. Vilnius: Eugrimas, 2001. 283 p. (On Diplomacy: A Genealogy of Western Estrangement: Hardcover, Blackwell Publishing Limited).

DILZELBACHER, Peter. (1998). Europos mentaliteto istorija: pagrindiniu temu apybraižos (Historia de la mentalidad europea: Apuntes sobre los temas principales) Vilnius: Aidai, 1998. $589 \mathrm{p}$.

DOBLATOV, S. The Zone (1985). Knopf. 1st Editon. 177 pages.

DUBY, Georges. (2004). Katedru laikai: menas ir visuomene 980-1420. (Los tiempos de las catedrales: arte y sociedad) Vilnius: Vilniaus dailès akademijos leidykla, 2004. 372 p.

EBAN, A. The New Diplomacy (London: Weidenfeld \& Nicolson, 1983), pp. 384-5.

EDELMAN, Murray. (1964). The Symbolic Uses of Politics. Illinois: University of Illinois Press, 1985. $232 \mathrm{p}$.

ELIAS, N. Rümu dvaro visuomene.(Vilnius: Aidai, 2004). 307 p.

FREY, Linda, FREY, Marsha. "The Reign of the Charlatans Is Over": The French revolutionaty Attack on Diplomatic Practice // The Journal of Modern History. Vol.65, Nr.4. (Dec., 1993), pp.706-744.

GOFFMAN, Erving. (1972). Relations in Public: Microstudies of the Public Order. New York: Harper \& Row, 1972. 396 p.

HEATH, R. L. \& BRYANT, J. (2000). Human Communication Theory And Research (second edition). Mahwah, New Jersey: Lawrence Erlbaum Associates, Inc., Publishers.

HUNT, Lynn. (1984). Politics, Culture, and Class in the French Revolution. Los Angeles: University of California Press, 1984. 270 p.

ISEN, Instituto del Servicio Exterior de la Nación (ISEN), Enlace en la red: http://www.isen.gov.ar/

JIMENEZ, Silvia. El Protocolo, herramienta para la comunicación creativa [interactivo]. [Acceso 20-V-2008] Enlace en la $<$ http://www.tercermilenio.ucn.cl/e14/periodismo_comunicaciones_jimenez.html $>$.

JÖNSON C., Hall M. (2003) Communication: An Essential Aspect of Diplomacy. International Studies Perspectives (2003) 4, 195-210.

JÖNSON C., HALL M. (2005) Essence of Diplomacy. New York: Palgrave Macmillan. MATTINGLY G. (1988) Renaissance Diplomacy. New york: Dover Publications, Inc. MAYER, A. (1981). The Persistence of the Old Regime: Europe to the Great War. New York. 1981. p. 136).

MELISSEN J., (2002) "Summit Diplomacy Coming of Age," Discussion papers in Diplomacy. Netherlands Institute os International Relations „Clingendael“. 
ROGERS E.M., KINCAID D.L. (1981) Communication Networks: Towards a New Paradigm for research. New York: Free Pres.

ROOSEN, William (1980). Early Modern Diplomatic Ceremonial. A Systems Approach. The Journal of Modern History, 1980, Nr. 3, p. 452-476.

SHRAMM W. (1973) Men, Messages and Medium: A look at Human Communications. New York: Harper and Row.

SANABRIA, F. (1974): Radiotelevisión, comunicación y cultura, Confederación de Cajas de Ahorro, Fondo para la investigación económica y social.

SPERBER D. WILSON D. Relevance: Communication and cognition. Cambridge: Harward University Press, 1986.

TUBBS, S.L. \& MOSS, S. (1983). Human Communication (4th edition). New York: Random House, Inc.

VAN WICKEFORT A. L'Ambassadeur et ses fonctions. (De Wickefort, Abraham. The Ambassador and his functions. Microfilm. Woodbridge, CT Research Publications, Inc., 1986. 1 reel; 35mm. (The Eighteenth Century; reel 4884, no. 2). (De Wickefort, Abraham. The Ambassador and his functions. (1995) Routledge.

КАБАНЕС, Огюстен, НАСС, Леонард. (1988). Революционный невроз. Москва: Институт пси у ологии РАН, Издательство КСП+, 1988. 576 с. (CABANES, Augustin у NASS, Lucien, La neurosis revolucionaria, Madrid, Ediciones Mercurio).

КУЗНЕЦОВ, Игорь Н. (2002). Этикет (деловой, дипломатический, повседневный). Минск Амалфея, 2002. 464 с. (Kuznetsov, Etiqueta (empresarial, diplomática y cotidiana). Minsk, 2002) 